\title{
REPORTE DE NUEVOS EJEMPLARES DE LA EMISIÓN DEL PAPEL MONEDA EN PUERTO RICO (1781)
}

\section{REPORT OF NEW COPIES OF THE ISSUANCE OF PAPER MONEY IN PUERTO RICO (1781)}

\author{
ÁNGEL O. NAVARRO ZAYAS \\ Universidad de Puerto Rico, Recinto de Ponce \\ Caribbean University, Recinto de Ponce
}

\begin{abstract}
Resumen: En nuestro artículo exponemos y hacemos un breve análisis sobre la emisión de papel moneda (1781) en Puerto Rico bajo el reinado de Carlos III, el cual entendemos responde a la falta del Situado Mexicano y a la guerra entre España e Inglaterra. Hubo una emisión previa de papel moneda (1766), debido a la falta del Situado Mexicano que llegaba anualmente a Puerto Rico. Muy poco se conoce sobre la historia de ambas emisiones, sin embargo la emisión de papel moneda de 1766 y esta emisión de 1781, hacen que Puerto Rico figure como el primer país en Hispanoamérica en emitir papel moneda, y a su vez sugerimos que la imprenta rudimentaria existía en la Isla 25 años antes de lo comúnmente aceptado entre los historiadores de Puerto Rico (1806).

Palabras-clave: Puerto Rico, papel moneda, Siglo XVIII.
\end{abstract}

\begin{abstract}
In our paper we present and make a brief discussion of the issuing of paper money (1781) in Puerto Rico under the reign of Charles III (Carlos III), in response to the lack of the "Situado Mexicano" and the war between Spain and England. There was a previous issue of paper money in 1766, due to the lack of the "Situado Mexicano" which was supposed to be received annually in Puerto Rico. Very little is known about the history of both issues, but the issue of paper money in 1766 and this issue of 1781, entitles Puerto Rico to be listed as the first country in Latin America (still under Spanish rule) to issue paper money; also, evidence suggests that rudimentary printing existed on the island 25 years before the commonly accepted date among historians in Puerto Rico (1806).
\end{abstract}

Keywords: Puerto Rico, paper money, XVIII Century.

\section{INTRODUCCIÓN.}

Puerto Rico recibió anualmente desde el Virreinato de Nueva España, una cantidad de dinero o 'situado', también conocido como el Situado Mexicano. La isla recibió este dinero por un espacio aproximado de 222 años (1587-1809) y finalizó formalmente dicho subsidio cuando en México comenzaron las insurrec- 


\section{ÁNGEL O. NAVARRo ZAYAS}

RePorte DE NUEVos EJEMPLARES DE LA EMISIÓN DEL PAPEL MONEDA EN PueRto Rico (1781)

ciones que culminaron con su independencia. En el caso de no llegar a Puerto Rico dicho Situado Mexicano la isla se veía sumida en una gran crisis económica. En la segunda mitad del Siglo XVIII, durante el reinado de Carlos III, cuando España luchaba en contra de Inglaterra, apoyando el recién nacido Estados Unidos de América, una de las medidas con efectos negativos sobre el funcionamiento del país como consecuencia de la ausencia del Situado Mexicano fue la institucionalización de la emisión de papel moneda, o la llamada "moneda provisional de papeletas". La primera emisión de papeletas se hizo en el año 1766 por la falta del Situado.

\section{DISCUSIÓN.}

El numismático Luis A. Rodríguez Vázquez (2004), escribió que en Puerto Rico, por Real Orden del 22 de agosto de 1766 fue autorizada una emisión de papel moneda con la cual se esperaba resolver la crisis [en Puerto Rico]. Esta es la emisión de papel moneda más antigua que se conoce para Puerto Rico, siendo la Isla la primera de las colonias españolas en América en hacerlo. Al año siguiente, por orden de julio de 1767, volvieron a emitirse más billetes reiterándose que los mismos serían redimidos al recibirse el Situado $^{2}$ bajo la incumbencia del Gobernador Marcos Vergara.

Citando textualmente a Pedro Tomás de Córdoba afirma sobre la emisión de 1766 en Puerto Rico:

La falta de oportunos situados de Méjico para la guarnicion que fué aumentada y para las obras de fortificacion, causaron en la Isla la mayor penuria, y como desgraciadamente se hubiese esperimentado un furioso huracán el 19 de Setiembre, que se repitió en 7 y 8 de Octubre, llegó la miseria á su colmo, no bastando los préstamos que se hicieron al Gobierno, el cual tuvo que emitir papeletas de 8 reales, en falta de moneda, estinguibles con el situado, que por último se recibió en cantidad de 271.929 pesos, 6 tomines y 6 granos, y 100,000 mas para la fortificacion, con cuyo auxilio se recogió una parte del papel, y se pagaron 50,993 pesos seis reales de los préstamos. ${ }^{3}$

Don Pedro Tomás de Córdoba, continuaba afirmando referente al Situado Mexicano y las papeletas, que en Puerto Rico en el año 1768:

${ }^{1}$ J. CRESPO ARMÁIZ, Fortalezas y Situados. La Geopolítica española en el Gran Caribe y sus efectos sobre el desarrollo económico y monetario de Puerto Rico (1582-1809), San Juan, 2005, p. 73.

${ }^{2}$ L. A. RODRÍGUEZ VÁZQUEZ, La Crisis del Papel Moneda en Puerto Rico. Monografías Numismáticas de Puerto Rico, vol. I, Ponce, 2004, p.5.

${ }^{3}$ P. T. DE CÓRDOBA, Memorias Geográficas, Históricas, Económicas y Estadísticas de la Isla de Puerto-Rico, vol. III, San Juan, 1832, pp. 29-30. 
Por otra de 15 de Febrero de 1768.... En el mes de Marzo llegó á la plaza el regimiento de Toledo para relevar el de Leon, el cual salió de ella el 29 de Abril. Con la llegada del situado se recogieron las papeletas que estaban en circulacion... ${ }^{4}$

Según Luis A. Rodríguez Vázquez (2004), en 1769 el Gobernador General Don Miguel Muesas, al arribar a isla el Situado Mexicano, pudo amortizar y sacó de circulación 88,000 pesos en papeletas. ${ }^{5}$

El historiador Humberto Burzio, escribió en 1958 referente al papel moneda en Puerto Rico, hizo un breve recuento de nuestra historia monetaria, pero no menciona el dato de Pedro Tomás de Córdoba. El afirmó lo que cito textualmente a continuación:

Puerto Rico tiene el privilegio de haber sido seguramente la primera posesión española de América que emitió billetes papel por falta de moneda metálica. Ocurrió este singular hecho dentro de la política monetaria hispanoamericana en 1810, con motivo de no haber llegado el "situado" que periódicamente era enviado desde el continente con los recursos necesarios para satisfacer los compromisos de las autoridades de la intendencia de la isla. La insurrección mexicana agravó la situación por quitarle su principal fuente de entrada de dinero, pues los gastos de la administración española eran muy superiores a los recursos de la isla. Para salvar el déficit, el gobierno se vio en la necesidad de emitir papel moneda, llamado "papeleta", y asignarle un curso forzoso, pero, como estaba sin la garantía del metálico, sufrió una gran depreciación. La crisis fue salvada con la introducción de moneda macuquina, la que estuvo en circulación en la isla hasta el año 1857, en que se dispuso su recojo. ${ }^{6}$

Sin embargo el único libro que hace una referencia explícita a un documento primario se encuentra en el libro inédito de Jaime González del año 1934 donde, Manuel Egozcue transcribió documentos del Archivo General de Puerto Rico para González, lo siguiente:

Real Orden relacionada con la emisión de papel moneda en el año de 1781.

Prevengo a V.S. y Vms. de orden del Rey que inmediatamente procuren recoger, si ya no lo hubieren hecho, todas las Papeletas que en calidad de Moneda se distribuyeron por esas Reales Cajas con motivo de la falta de los "situados" en el año pasado de 1780. Dios guarde a V.S. y Vms. muchos años.

Aranjuez, 16 de Junio de 1781.

Sr. Capitán General de Puerto Rico ${ }^{7}$

Don Pedro Tomás de Córdoba nos menciona nuevas emisiones de papel moneda en Puerto Rico, a quien citamos:

${ }^{4}$ P. T. DE CÓRDOBA, Memorias Geográficas, Históricas, Económicas y Estadísticas de la Isla de Puerto-Rico, vol. III, San Juan, 1832, p. 31.

${ }^{5}$ L. A. RODRÍGUEZ VÁZQUEZ, La Crisis del Papel Moneda en Puerto Rico. Monografias Numismáticas de Puerto Rico, vol. I, Ponce, 2004, p. 6.

${ }^{6}$ H. F. BURZIO, Diccionario de la Moneda Hispanoamericana, vol. II, Santiago, 1958, p. 279. 105.

7 J. GONZÁLEZ, El Problema Monetario de Puerto Rico [Libro inédito], San Juan, 1934, p. 
Desde 17 de Julio de 1781, en que empezaron á emitirse papeletas por la falta oportuna de situados, hasta fin de Marzo de 1785 se crearon 654,325 pesos, y al tiempo de su estincion se hallaron demas 25,233 ps. 2 rs. $^{8}$

El Dr. Eduardo Rodríguez-Vázquez indica en el libro de Humberto Costa (2007), en donde nos narra:

...sobre el advenimiento de la imprenta en Puerto Rico, o el atisbo de lo que será su aparición formal, aunque sería tardía, en 1806 (ciento ochenta años después que a México, casi cuarenta después que a Perú...). ${ }^{9}$

Sobre el papel moneda en Puerto Rico él cita a Pedro Tomás de Córdoba, sobre la emisión de 1766 y a Humberto Burzio, en que, Puerto Rico fue el primero en emitir papel moneda en Hispanoamérica. El Dr. Rodríguez-Vázquez continuó afirmando:

...Le siguen en la emisión de papel moneda Santiago de Cuba en 1781, Santo Domingo en 1782, y España en 1783. Hasta el presente no ha aparecido evidencia que confirme esta aseveración. [He aquí nuestro hallazgo, la emisión de 1781]. Sin embargo, de haber ocurrido así habría sido la consecuencia lógica de tener que cubrir necesidades urgentes en una situación precaria. Es decir, que aunque la labor de cada papeleta sea esencialmente manual, el término 'impreso' implica estampado, y para el caso en particular, sean números o letras, o ambos, ello significa la confección de tipos, muy probablemente xilográficos (en madera). El problema de la escasez de numerario y la consecuente emisión de papeletas continuó ocurriendo hasta finales del siglo XVIII y principios del XIX. Las primeras papeletas probablemente eran muy similares a las de Santo Domingo de 1782. Para esta fecha, aún seguía sin llegar la imprenta a Puerto Rico. ${ }^{10}$

Sin embargo [énfasis nuestro] según se desprende de la evidencia y de la descripción en el Catálogo en línea del Portal de Archivos Españoles, menciona que son grabados impresos [ver descripción del catálogo en línea], donde, según nuestro parecer son xilografías. Al consultar con la Directora del Departamento de Humanidades de la Universidad de Puerto Rico, Recinto de Ponce, la Prof. Margarita Balmaceda (pintora), ella nos indicó que el papel moneda probablemente fue fabricado mediante el grabado en madera (xilografía). Según la Real Academia Española la xilografía es definida como:

1. Arte de grabar en madera.

2. Impresión tipográfica hecha con planchas de madera grabadas.

No creemos que el papel moneda haya sido fabricado con tipos en metal ya, que según hemos publicado en la revista anual Numiexpo 2010 de la Sociedad

${ }^{8}$ P. T. DE CÓRDOBA, Memorias Geográficas, Históricas, Económicas y Estadísticas de la Isla de Puerto-Rico, vol. III, San Juan, 1832, pp. 29-30.

${ }^{9}$ H. COSTA, Los Billetes de la Isla de Puerto Rico, Colección Humberto Costa, Mayagüez, 2007, pp. 31-32.

${ }^{10}$ H. COSTA, Los Billetes de la Isla de Puerto Rico, Colección Humberto Costa, Mayagüez, 2007, pp. 31-32. 
Numismática de Puerto Rico ${ }^{11}$ referente a la posibilidad de moldes para grabar en metal en Puerto Rico, para una contramarca o resello, encontrado en una moneda de Carlos IIII, es interesante observar que al ser citados en secreto [en el año 1795], los maestros plateros de la Ciudad de San Juan — los señores Don Manuel Moxica y Don Pedro Elias sobre un aparente lema sedicioso en una monedaambos evaluaron la moneda e indicaron y cito: "...Que ambos letreros son iguales, y aseguran que esta operación no es hecha en esta ciudad, ni en la Isla, porque no hay quien haga un molde para grabar de letras tan perfectas..." La contramarca encontrada en la moneda leía: LIGHT.

Por tanto muy humildemente nos atrevemos a sugerir que en Puerto Rico ya se utilizaban técnicas de impresión rudimentarias en 1781, casi 25 años antes, como bien señala el Dr. Rodríguez Vázquez, como la fecha de la llegada de la imprenta en Puerto Rico (1806). Entendemos que el grabado en madera (xilografía) es una forma reproducción impresa, por tanto, creemos que ya había imprenta en Puerto Rico en 1781. La llegada de la imprenta se calcula para el año 1806 y es la común aceptación por la mayoría de los historiadores en Puerto Rico. Este papel moneda es el más antiguo que se ha reportado hasta el momento en Puerto Rico [todavía no han aparecido papeletas de 1766] y a su vez probablemente es uno de los más antiguos reportados en toda Hispanoamérica como se desprende del libro de Humberto Burzio.

En nuestra búsqueda con el fin aportar un poco a los conocimientos sobre la numismática y la política monetaria en Puerto Rico cuando fue una colonia española, localizamos en el Catálogo del Portal de Archivos Españoles (http://pares.mcu.es/) 4 ejemplares de papel moneda de Puerto Rico. Los mismos se encuentran custodiados en el Archivo de Indias en Sevilla; el papel moneda aunque no lo podíamos ver en línea, le peticionamos al personal del Archivo si los podían reproducir y ellos muy gentilmente, a vuelta de correo, nos remitieron copia de las fotografías digitales del papel moneda. Nuestro más sincero agradecimiento a todo el personal que labora en el Archivo de Indias en Sevilla, quienes hacen posible, que investigadores al otro lado del Atlántico, podamos llevar a cabo nuestras investigaciones. El personal del Archivo nos remitió copia digital de 2 ejemplares de papel moneda de 8 Reales y 2 ejemplares de 4 Reales. Ellos son los que siguen a continuación:

${ }^{11}$ A. O. NAVARRO ZAYAS, "Documentos históricos sobre la Primera Contramarca reportada en Puerto Rico y del primer dibujo Numismático Criollo", Numiexpo 2010 (2010), p. 158. 

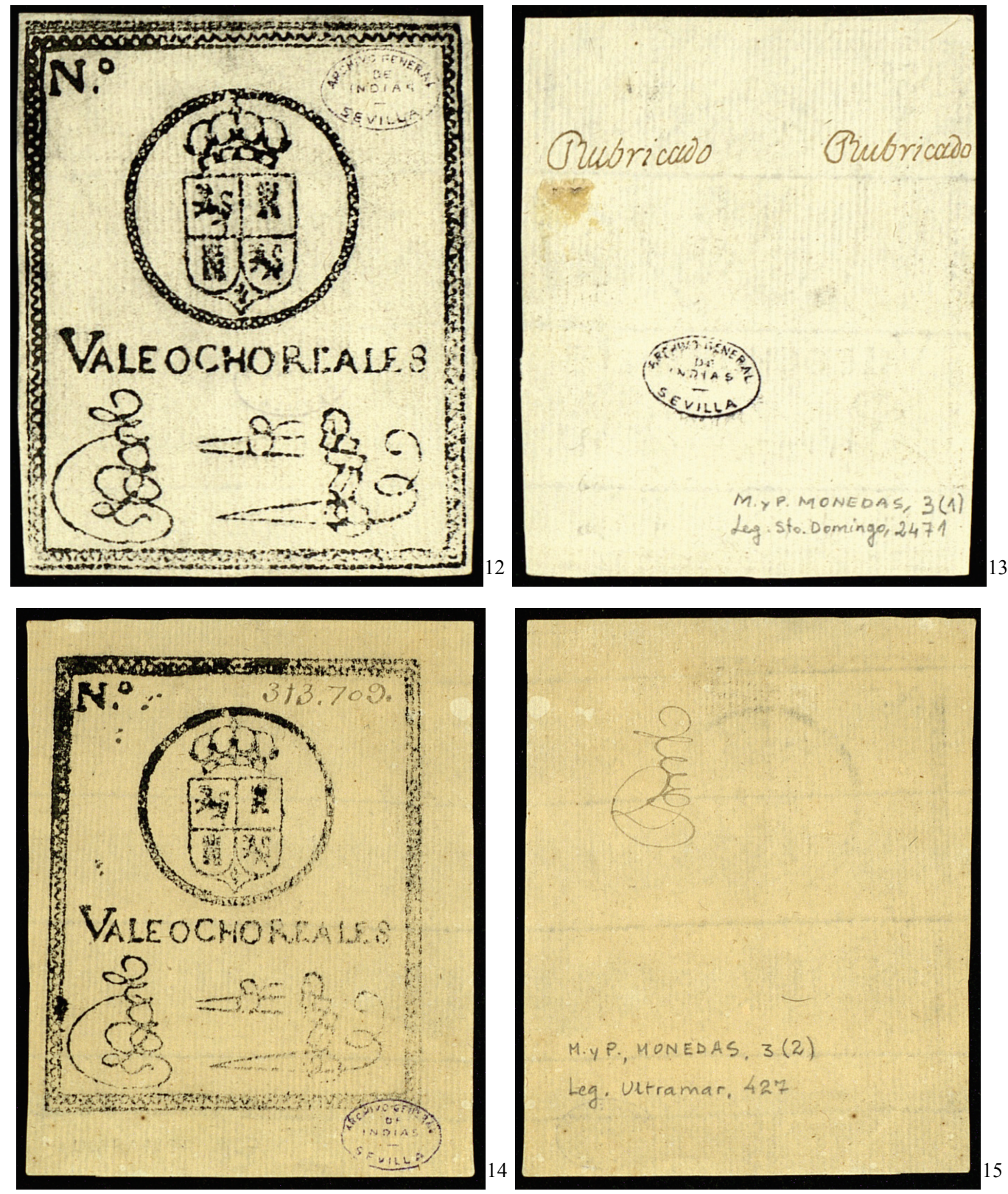

${ }^{12}$ Figura 1a. Archivo General de Indias (AGI), "Vale de 8 reales". MP-MONEDAS,3(1). [Parte Frontal]. Según la descripción del catálogo en línea del Portal de Archivo Españoles (http://pares.mcu.es/) lee como sigue: Vale de 8 reales de curso en Puerto Rico. Rubricado. Con escudo real grabado. Grabado; todo el documento impreso. Tamaño: Alto: 90 Ancho: $73 \mathrm{MM}$ en Soporte: Papel (1 hoja). Remitido por el gobernador de Puerto Rico dando cuenta de haber habilitado papeletas por falta de moneda, a consecuencia de haber agotado la guerra las existencias de las cajas reales (Puerto Rico, 27 de octubre de 1781). ${ }^{13}$ Figura 1b. Archivo General de Indias (AGI), "Vale de 8 reales". MP-MONEDAS,3(1).
[Reverso].

${ }^{14}$ Figura 2a. Archivo General de Indias (AGI), "Dos vales de 8 reales con el número 313.709, de curso en Puerto Rico." MP-MONEDAS,3(2). [Parte Frontal] Según la descripción 

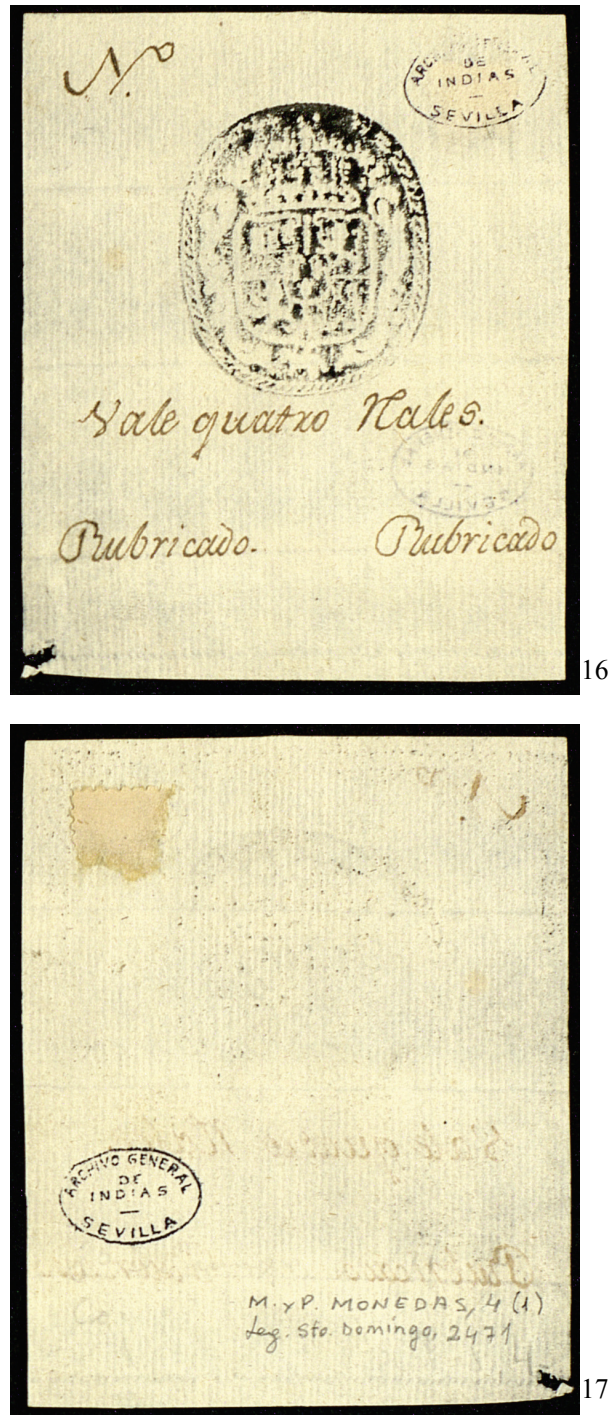

del catálogo en línea del Portal de Archivo Españoles (http://pares.mcu.es/) lee como sigue: Rubricados. Con escudo real grabado. Son dos ejemplares del vale.

Grabado; todo el documento, excepto el número, impreso. Tamaño: Alto: 16 Ancho: 85 MM en Soporte: Papel (2 hojas). Remitidos con carta de Gabriel Tinajero, tesorero oficial real de las cajas de Puerto Rico, a Antonio Ventura de Taranco, dando cuenta de haber habilitado unas papeletas para pagar a las tropas por falta de dinero (Puerto Rico, 30 de octubre de 1781).

15 Figura 2b. Archivo General de Indias (AGI), "Dos vales de 8 reales con el número 313.709, de curso en Puerto Rico." MP-MONEDAS,3(2). [Reverso]

16 Figura 3a. Archivo General de Indias (AGI), "Vale de quatro reales." MPMONEDAS,4(1). [Parte Frontal]. Según la descripción del catálogo en línea del Portal de Archivo Españoles (http://pares.mcu.es/) lee como sigue: Grabado y manuscrito. Vale real de curso en Puerto Rico. Estampado el sello con escudo real. La titulación y demás indicaciones manuscritas. Tamaño: Alto: 90 Ancho: 73 MM en Soporte: Papel (1 hoja). Remitido con carta del gobernador de Puerto Rico dando cuenta de haber habilitado papeletas por falta de moneda, a consecuencia de haber agotado la guerra las existencias de las cajas reales (Puerto Rico, 27 de octubre de 1781). 


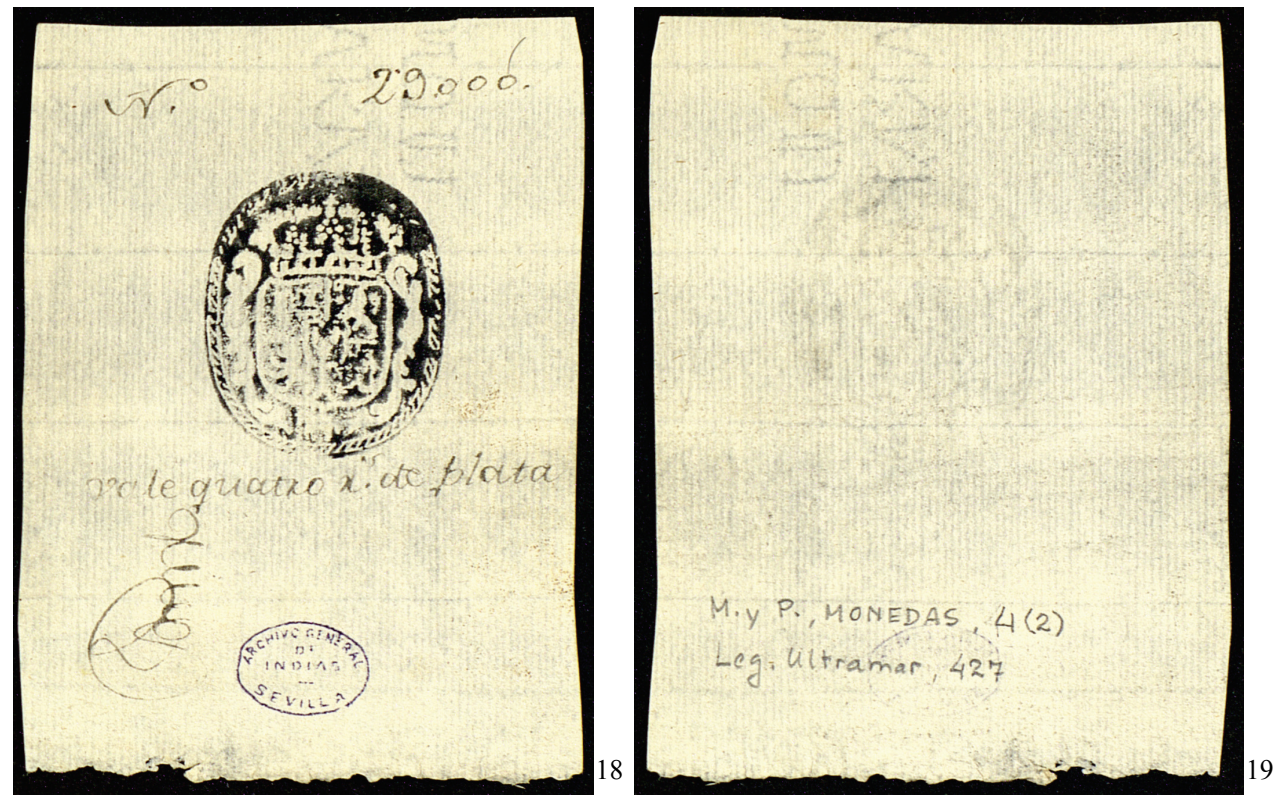

\section{CONCLUSIÓN.}

Este papel moneda de (1781) en denominaciones de 8 Reales y de 4 reales son los más antiguos reportados hasta hoy para Puerto Rico, y probablemente nos atrevemos a afirmar que según lo investigado son también las emisiones más antiguas, hasta el momento, reportadas para Hispanoamérica. Podemos observar que las papeletas están impresos por un solo lado (unifaciales). Ambos ejemplares de papel moneda de 8 Reales y Reales, tienen las rúbricas de Gabriel Tinajero, las de 8 Reales tienen otras dos rúbricas ilegibles; ambos ejemplares tienen el sello real español.

17 Figura 3b. Archivo General de Indias (AGI), "Vale de quatro reales." MPMONEDAS,4(1). [Reverso].

${ }^{18}$ Figura 4a. Archivo General de Indias (AGI), "Dos vales de cuatro reales de plata con el número 29.000, de curso en Puerto Rico.” MP-MONEDAS,4(2). [Parte Frontal]. Según la descripción del catálogo en línea del Portal de Archivo Españoles (http://pares.mcu.es/) lee como sigue: Rubrica. Con escudo real grabado. Véase MP-MONEDAS,3(2) Dos ejemplares. Remitidos con carta de Gabriel Tinajero, tesorero oficial real de las cajas de Puerto Rico, a Antonio Ventura de Taranco, dando cuenta de haber habilitado unas papeletas para pagar a las tropas por falta de dinero (Puerto Rico, 30 de octubre de 1781). Tamaño: Alto: 170 Ancho: 190 MM en Soporte: Papel (2 hojas). Grabado.

${ }^{19}$ Figura 4b. Archivo General de Indias (AGI), "Dos vales de cuatro reales de plata con el número 29.000, de curso en Puerto Rico.” MP-MONEDAS,4(2). [Reverso]. 



Figura 5. Rúbricas y firmas de Gabriel Tinajero y el Gobernador José Dufresne.

Como se desprende de las rúbricas aquí evidenciadas: la del Gobernador José Dufresne no figura en ningún lugar del papel moneda. Según las fuentes primarias disponibles al momento de preparar esta investigación observamos que en efecto el papel moneda fue emitido en Puerto Rico. A continuación, citamos textualmente un fragmento de la transcripción de la carta del Gobernador Dufresne enviada a España, la cual lee así:

Número 158.

Excelentísimo Señor

Da cuenta del valim ${ }^{\text {to }}$. de Papeletas por falta de moneda, para subrogar su importancia interin se reciven los situados devengados.

Muy Señor mío:

Haviendose consumido los fondos de esta Reales Cajas por la falta de los situados de su dotación durante la presente Guerra y sus crecidas atenciones, con el aumento de la guarnición, y otros gastos regulares de este tiempo, sin embargo de haberse minorado los que admiten aorro, y recogido los préstamos posibles; me hallé en el último recurso de valerme de Papeletas que en calidad de moneda subrogasen su falta, e importancia, interin se reciben los situados devengas según se ha practicado en anteriores urgencias: A este fin se formaron dichas Papeletas de dos especies, unas de valor de ocho reales y otras de quatro, numeradas, selladas con las Reales Armas, y rubricadas de oficiales Reales en la forma que manifiestan las dos que acompaño as [sic] para el más claro conocimiento y quedan corriendo en esta Ysla desde el próximo pasado Julio que empezaron a distribuirse por la Real Contaduría;...Puerto Rico 27 de octubre de 1781.

Joseph Dufresne ${ }^{20}$.

En el documento anterior, hemos ennegrecido el texto pertinente a la emisión de las papeletas por la falta de monedas del Situado Mexicano; en ella hace

${ }^{20}$ Archivo General de Indias (AGI), SANTO DOMINGO, 2471. 


\section{Ángel O. NAVARro Zayas}

REPORTE DE NUEVOS EJEMPLARES DE LA EMISIÓN DEL PAPEL MONEDA EN PUERTo Rico (1781)

mención explícita de la fabricación de las denominaciones de 8 Reales y de 4 Reales.

En el segundo documento al cual hemos podido tener acceso, al parecer es redactado por Gabriel Tinajero y por circunstancias la cual desconocemos, él hace mención que se encontraba preso [ver texto completo en el APENDICE], pero aun trabajaba para el gobierno español en Puerto Rico. Citamos textualmente parte del documento a continuación:

...considere V.S. el descanso, que tendrán y lo que sucede es que tiran solo a salir del día, a lo que se ha añadido por falta de Dinero a fin de evitar algún desorden entre la tropa formar unas papeletas como las adjuntas que corren como tal en toda la Ysla... ${ }^{21}$

El documento se hace mención y es afirmado que el papel moneda circulaba “...como tal en toda la Ysla..." y al parecer no se circunscribió únicamente a la ciudad amurallada de San Juan. Continuando con el mismo documento, leemos que fue hecho un trabajo de "estampar" las papeletas y que al parecer el trabajo fue hecho en la noche. Esto podría tener sentido si el estampado se hizo en la noche y que en el transcurso de la mañana y la tarde, el calor del día, secara la tinta en las papeletas.

...para cuyo trabajo de estampar ha obligado traer los Guardas; y algunos particulares voluntarios por evitarle gasto al Rey las quales corren desde primero de Julio de este año, de suerte que llega el número de las de ocho Reales a 313.709 y de las de a quatro reales a 29.000 las quales llevo rubricadas, sin las firmas, que echo por razón de los dichos empleos no contando con las que se renuevan incesantemente ascendiendo el número de las que rubrico Diariamente de 2500 a 39 - en tal conformidad que para dar cumplimiento obliga emplear la mas para de la noche, y lo peor es ignorarse quando se acabará esta tarea por no tenerse noticia alguna de venir los situados que faltan desde antes de la Guerra... ${ }^{22}$

No sería la primera vez que evidenciamos la fabricación del papel moneda durante la noche, ya que parte de la fabricación y numeración de los Billetes de Canje (1895) en España, fue llevado a cabo en la noche. ${ }^{23}$

Al momento de llevar a cabo esta investigación, solamente hemos podido disponer de 2 fuentes primarias [las cuales son las discutidas en esta conclusión] para tratar de reconstruir un poco la realidad de la emisión de estos papeles monedas [Ambas cartas fueron transcritas por el autor y se encuentran al final de este

${ }^{21}$ Archivo General de Indias (AGI), ULTRAMAR, 427

${ }^{22}$ Ibid.

23 A. O. NAVARRO ZAYAS, Puerto Rico, Índice General de los Documentos Relativos al Canje de la Moneda Mejicana. 1895-1896. Expediente sobre canje de moneda mejicana que circula en la isla, Ponce, 2012, pp. 89-97. 
artículo como APÉNDICES]. Hemos recurrido a la literatura conocida entre numismáticos e historiadores para tener una idea un poco más clara sobre estos 2 pares de ejemplares de 8 y 4 reales.

Citando al Dr. Jorge Crespo Armáiz sobre este hallazgo del papel moneda (1781) el cual es custodio el Archivo General de Indias:

...se trata del mayor descubrimiento numismático de nuestra historia monetaria quizás en décadas. ${ }^{24}$

En la literatura numismática de Puerto Rico no se habían reportado antes fotografías de estas papeletas de 1781. No se han reportado nunca las papeletas de 1766 emitidas en Puerto Rico. De existir dicho papel moneda... ¿Dónde podrían encontrarse? ¿Estarán en las colecciones privadas, en los museos o en los archivos en España?

Esperamos que esta investigación sobre nuevos ejemplares de papel moneda estimule más aun el estudio de la numismática puertorriqueña y de nuestras hermanas Antillas caribeñas.

\section{AGRADECIMIENTOS.}

Quiero agradecer a la Junta de Directores de la Sociedad Numismática de Puerto Rico, pero muy en especial a su pasado Presidente, Don Rafael Echevarría y al Secretario, el Dr. Jorge Crespo Armáiz por su apoyo y por la aportación económica para llevar a cabo esta investigación. A la memoria del Padre del Coleccionismo del Papel Moneda de Puerto Rico, Don Humberto Costa. A mi amigo el Sr. Luis Antonio Rodríguez Vázquez por motivarme siempre en mis investigaciones y sus enseñanzas en la numismática.

Por último, agradezco a mi amada esposa Pilar Cristina por su cariño y paciencia de oro; y a nuestro queridísimo hijo, Lucas Mateo, para que algún día conozcas la rica historia monetaria de Puerto Rico y el Caribe...

\section{APÉNDICES.}

Número 158.

Excelentísimo Señor

Da cuenta del valim ${ }^{\text {to }}$. de Papeletas por falta de moneda, para subrogar su importancia interin se reciven los situados devengados.

\footnotetext{
${ }^{24}$ Mensaje de texto a los miembros de la Junta de Directores de la Sociedad Numismática el 22 de febrero de 2014.
} 
Muy Señor mío:

Haviendose consumido los fondos de esta Reales Cajas por la falta de los situados de su dotación durante la presente Guerra y sus crecidas atenciones, con el aumento de la guarnición, y otros gastos regulares de este tiempo, sin embargo de haberse minorado los que admiten aorro, y recogido los préstamos posibles; me hallé en el último recurso de valerme de Papeletas que en calidad de moneda subrogasen su falta, e importancia, interin se reciben los situados devengas según se ha practicado en anteriores urgencias: A este fin se formaron dichas Papeletas de dos especies, unas de valor de ocho reales y otras de quatro, numeradas, selladas con las Reales Armas, y rubricadas de oficiales Reales en la forma que manifiestan las dos que acompaño as [sic] para el más claro conocimiento y quedan corriendo en esta Ysla desde el próximo pasado Julio que empezaron a distribuirse por la Real Contaduría; lo que participo as [sic] para que se sirva acceder a la aprobación de este arvitrio, o prevenirme lo que más sea del Superior Real agrado.

Nuestro Señor que as [sic] los muchos años que deseo.

Puerto Rico 27 de octubre de 1781.

Excelentísimo Señor

Real Ministerio de Hacienda

Su más atento seguro señor,

Joseph Dufresne

Excelentísimo Señor Don Josef de Galvez. ${ }^{25}$

Muy Señor mío:

Bien conozco la molestia, que le doy con tanta repetición de Ynstancias, pero también conocerá V.S. los trabajos y quebrantos aunque no los padezca, que tiene, el que se halla en el estado, que yo estoy constituido, después de seis años que llevo ya de prisión, y con la esperanza, de no saber quando saldré de ella, de suerte, que mirando con cuidado, aun me hallo en peor disposición que los [sic] desterrados, pues estos cumplido su tpo, que nunca es tanto usan de su Libertad, y en su prisión (aunque diversa) por tener ellos Delito y yo no, gozan de más descanso; en esta atención, por que vea V.S que mis suplicas, y ruegos son justas, y que aunque se las tengo echas presente muchas vezes como se van Aumentando las repito pareciéndome que pues S.M. y demás del Consejo descuidan, y descansan en V.S. lograre algún alibio.

No ygnora V.S. (como que lo maneja) el pesso cargo y responsión que es en el Día; el Despacho de Aduana, todas las Administraciones y demás Ramos de Real Hacienda lo que se despacha como se deve por falta de Individuos pues es por esso pierde el Rey el cobro de muchísimos derechos, el encargo de la [sic] Contaduría Comisionada de Guerra de Exercito y man ${ }^{\mathrm{a}}$. Con tan crecida guarnición, como tiene [sic] dia esta plaza compuesta de

${ }^{25}$ Archivo General de Indias (AGI), SANTO DOMINGO, 2471. 
tres Regimientos Artillera algunas compañías sueltas, Milicias, la Plana Mayor, Yngens, Ymbals. Presids. Hospital Fortificaciones y demás cuyo despacho se haze solo con el oficial Real Contador Ynterino un oficial primario otro segundo y yo, considere V.S. el descanso, que tendrán y lo que sucede es que tiran solo a salir del día, a lo que se ha añadido por falta de Dinero a fin de evitar algún desorden entre la tropa formar unas papeletas como las adjuntas que corren como tal en toda la Ysla, para cuyo trabajo de estampar ha obligado traer los Guardas; y algunos particulares voluntarios por evitarle gasto al Rey las quales corren desde primero de Julio de este año, de suerte que llega el número de las de ocho Reales a 313.709 y de las de a quatro reales a 29.000 las quales llevo rubricadas, sin las firmas, que echo por razón de los dichos empleos no contando con las que se renuevan incesantemente ascendiendo el número de las que rubrico Diariamente de 2500 a 39 - en tal conformidad que para dar cumplimiento obliga emplear la mas para de la noche, y lo peor es ignorarse quando se acabará esta tarea por no tenerse noticia alguna de venir los situados que faltan desde antes de la Guerra: aora vea V.S. que tarea esta en unos climas como estos y en mi edad pero todo lo llevo con sumo gusto, por servir a mi Rey hasta dar el último aliento, pero es preciso me sea mui doloroso ver el modo y trato de este Governador: que no contento con haverse apropiado todas las facultades del empleo para usar de ellas en sus fines particulares en el mando, Autoridad y utilidad pero para la tarea, trabajo e incomodidad esso no deviendo usar de todo, si no que sin informarse por mero echo de escribir y perseguia el trato ilisito (quando el no ha salido de su casa dos veces en los cinco años que lleva de su Gobierno bueno) y se despidiese una Real Orden mandandoo que le imitaramos obligando a su observancia y de tal suerte que no hay tienda ni casa que no le tenga ni Yndividuo que no se emplee en esse trato. Y con todo esso estoy persuadido que según las representaciones echas por el Difunto contador y yo, tanto el Consejo como el Señor Galves, dexaran de decirlo algo pero el si es assi se dessentiende de todo y hace qual quiere de suerte que en este ultimo correo se observó que se quedaron dos pliegos que el uno parecía ver del Consejo rotulados para el y para mi los que le llevaron y se observó que quando los abrió y leyó se le oyó decir sumamente enfadado ya está echo y reecho [sic] váyanse a la mierda que me cago en todos, y otras muchas palabritas a este tenor de las que acostumbra y no se ha sabido que contenían puesto guardó como ha hecho con los demás diciendo no que no se le daba cuidado de nada: que el se ira por las Yslas Estrangeras que no aguarda el que lo vengan a mudar, ni la residencia que en la corte con poco lo tiene compuesto y el clavado clavado: Por lo que suplico a V.S. que se mueva a piedad y antes que acabe con migo que es el único que ha quedado como lo ha hecho con otros y últimamente con el obispo que murió en 20 de Agosto ultimo y haga presente a S.M. y los Señores del Consejo atiendan este particular mérito de las papeletas, treinta y siete años continuos de servicio y seis que va de prisión y suspensión sin delito para que lo- 
Ángel O. NAVARro Zayas

REPORTE DE NUEVOS EJEMPLARES DE LA EMISIÓN DEL PAPEL MONEDA EN PUERTo Rico (1781)

gre sino el Assenso ni otro Destino al menos el retiro con el sueldo que actualmente disfruto donde fuere del agrado de V.S. que puede que con esso se logre quietud y yo descanso. Assi lo espero de V.s. cuya vida guarde Dios muchos años como deseo. Puerto Rico 30 de Octubre de 1781.

B.L.M de V.S. su mas Atento Seguro Servidor.

Gabriel Tinagero

[rubrica]

Señor Don Antonio Bent ${ }^{\mathrm{a}}$ de Taranco. ${ }^{26}$

${ }^{26}$ Archivo General de Indias (AGI), ULTRAMAR, 427 